\title{
CORRESPONDENCE
}

\section{Noninvasive ventilation in severe stable COPD: is it effective, and if so, in what way?}

\section{To the Editors:}

We read with interest the systematic review of KOLODZIEJ et al. [1] about noninvasive positive-pressure ventilation (NPPV) in severe stable chronic obstructive pulmonary disease (COPD). First of all, we would like to compliment the authors on their excellent review. It is extremely important that good-quality reviews are published in the field of NPPV in severe stable COPD. The development of new therapeutic options in these patients is increasingly being recognised as urgently needed [2].

However, we would like to comment on the conclusions KolodzIEj et al. [1] draw in their review. They conclude that bilevel NPPV used in a select proportion of patients with severe stable COPD can improve gas exchange, exercise tolerance, dyspnoea, work of breathing, frequency of hospitalisation, health-related quality of life and functional status. Following this, they suggest an adjunctive role for the use of bilevel NPPV in the management of chronic respiratory failure due to COPD.

The first remark we would like to make is that their conclusions were based mostly on nonrandomised controlled trails (RCTs). Combined analysis of the results of the RCTs did not show the effect on arterial blood gases, exercise tolerance, work of breathing or hospitalisations. Evidence of an improved health-related quality of life was derived from only two studies $[3,4]$. Furthermore, in the study by GARROD et al. [4], the NPPV group had very low baseline Chronic Respiratory Questionnaire scores, which may have influenced their positive outcome.

Secondly, Kolodziej et al. [1] pooled studies that differed in length, control intervention and type of ventilation (daytime and nocturnal). They assessed their data on heterogeneity in study quality, patients, interventions and measurement of outcomes, and they showed that heterogeneity was evident in many parameters. This prohibits strong conclusions that NPPV is as effective in severe stable COPD.

In our opinion, in the review by KoloDzIEJ et al. [1], there was limited discussion about the importance of achieving effective ventilation. It is suggested that with higher hours of ventilatory use, greater reduction in hypercapnia can be achieved. While this might be true for nocturnal ventilation, with daytime ventilation, considerable effects might be achieved with a reduction in hours of NPPV use. Of the RCTs included, a significant reduction in hypercapnia during spontaneous breathing of room air was shown only in the study by DíAz et al. [5]. This study, and the more recent study of the same group [6], showed that considerable effects can be achieved with $3 \mathrm{~h}$ of NPPV during the daytime. During the night, increased upper airway resistance, decreased respiratory drive and less supervision might lead to delivery of a reduced volume to the patient. Therefore, correct monitoring of whether or not effective ventilation is achieved is very important, especially during the night. KolODZIEJ et al. [1] address this issue of more dynamic monitoring of effectiveness of NPPV. However, they imply that dynamic monitoring by transcutaneous measurements is preferable to arterial blood gases alone. Transcutaneous measurement of carbon dioxide with current techniques tends to drift overnight [7]. In our opinion, measuring multiple arterial blood gas samples during NPPV is the gold standard. Unfortunately, until now, no RCT has monitored the effectiveness of their intervention in this way.

Our second remark relates to the importance of using high inspiratory pressures. Even higher pressures than used in most RCTs might be necessary to achieve normocapnia [8], although no clear evidence exists on exactly how high pressures should be.

Finally, we would like to comment on the selection of appropriate patients. Patients with very severe COPD seem to benefit most. KolodZIEJ et al. [1] emphasise that patients with severe hyperinflation may benefit most. However, too little evidence currently exists to make a clear statement about whether patients should be selected on the basis of the severity of chronic respiratory failure, hyperinflation or the height of the work of breathing.

To conclude, while the review of KolodzIEJ et al. [1] is timely and a major contribution, we feel the strength of the conclusions is overstated. With this review in hand, some of the gaps in our knowledge are carefully uncovered, which should lead to well-designed randomised controlled trials of sufficient power. Some are undoubtedly underway.

\section{M.L. Duiverman, F.M. Struik and P.J. Wijkstra}

Dept of Pulmonary Diseases/Home Mechanical Ventilation, University Medical Center Groningen, University of Groningen, the Netherlands.

\section{STATEMENT OF INTEREST}

None declared.

\section{REFERENCES}

1 Kolodziej MA, Jensen L, Rowe B, Sin D. Systematic review of noninvasive positive pressure ventilation in severe stable COPD. Eur Respir J 2007; 30: 293-306.

2 Ambrosino N, Goldstein R. Series on comprehensive management of end-stage COPD. Eur Respir J 2007; 30: 828-830. 
3 Clini E, Sturani C, Rossi A, et al. The Italian multicentre study on noninvasive ventilation in chronic obstructive pulmonary disease patients. Eur Respir J 2002; 20: 529-538.

4 Garrod R, Mikelsons C, Paul EA, Wedzicha JA. Randomized controlled trial of domiciliary noninvasive positive pressure ventilation and physical training in severe chronic obstructive pulmonary disease. Am J Respir Crit Care Med 2000; 162: 1335-1341.

5 Díaz O, Bégin P, Torrealba B, Jover E, Lisboa C. Effects of noninvasive ventilation on lung hyperinflation in stable hypercapnic COPD. Eur Respir J 2002; 20: 1490-1498.

6 Díaz O, Bégin P, Andresen M, et al. Physiological and clinical effects of diurnal noninvasive ventilation in hypercapnic COPD. Eur Respir J 2005; 26: 1016-1023.

7 Storre JH, Steurer B, Kabitz HJ, Dreher M, Windisch W. Monitoring of transcutaneous $\mathrm{PCO}_{2}$ during initiation of noninvasive positive pressure ventilation. Chest 2007; 132; 1810-1816.

8 Windisch W, Kostić S, Dreher M, Virchow JC Jr, Sorichter S. Outcome of patients with stable COPD receiving controlled noninvasive positive pressure ventilation aimed at a maximal reduction of $\mathrm{PaCO}_{2}$. Chest 2005; 128: 657-662.

DOI: 10.1183/09031936.00168207

\section{From the authors:}

We thank M.L. Duiverman, F.M. Struik and P.J. Wijkstra for the relevant comments and agree that development of new therapeutic options in severe-stable chronic obstructive pulmonary disease is required.
We concur that the results are based mainly on nonrandomised controlled trials that exhibited considerable heterogeneity. Furthermore, factors such as achieving effective ventilation, determining inspiratory pressures and selecting patients who benefit most are only some of the areas identified that need further study. Clearly there are knowledge gaps. Most studies reviewed limited the ability to draw conclusions, with further research needed in order to confirm positive findings related to noninvasive ventilation in severe-stable chronic obstructive pulmonary disease patients. This and other techniques require testing in carefully designed and conducted trials, for which there were few.

Our rationale for conducting this review was to assess what is known and not known. Based on the existing evidence, noninvasive ventilation may have an adjunctive role in the management of chronic respiratory failure due to chronic obstructive pulmonary disease.

\section{M.A. Kolodziej*, L. Jensen ${ }^{\#}$, B. Rowe ${ }^{\top}$ and D. Sin ${ }^{+}$}

Depts of *Pulmonary Medicine, and "Emergency Medicine, Faculty of Medicine and Dentistry, University of Alberta Hospitals, and "Faculty of Nursing, University of Alberta, Edmonton, $\mathrm{AB}$, and ${ }^{+}$Division of Internal Medicine, St. Paul's Hospital, Vancouver, BC, Canada.

\section{STATEMENT OF INTEREST}

None declared.

DOI: $10.1183 / 09031936.00002708$

\section{Is air travel safe for those with lung disease?}

\section{To the Editors:}

I read with interest the article of COKER et al. [1] regarding the safety of commercial air travel for patients with lung disease. This is an area of concern since both the prevalence of chronic obstructive pulmonary disease and the number of people flying for leisure purposes are increasing. The available guidelines are based on very limited scientific evidence. Owing to the lack of data and potential adverse consequences of hypoxaemia induced by air travel, the recommendations proposed by scientific societies and panel guidelines are purposefully cautious.

The prospective evaluation of a large cohort such as the one described by COKER et al. [1] is of great value for increasing knowledge in this field, and potentially for the refinement of recommendations for patients planning air travel. If patients included in the study of COKER et al. [1] were indeed managed according to guidelines, it can be concluded that these guidelines are appropriate for predicting safe air travel. It could be argued, however, that current guidelines are too restrictive or cautious. The guidelines all recommend avoidance of hypoxaemia below an arterial oxygen tension $\left(\mathrm{Pa}, \mathrm{O}_{2}\right)$ of $6.7 \mathrm{kPa}(50 \mathrm{mmHg})[2-4]$ or $7.3 \mathrm{kPa}(55 \mathrm{mmHg})[2,5]$.

Bearing this in mind, it would be of great value to the scientific community to obtain the following additional information, which is probably already available to COKER et al. [1]. 1) How many patients with an arterial oxygen saturation measured by pulse oximetry $\left(\mathrm{Sp}_{\mathrm{p}} \mathrm{O}_{2}\right)$ of $92-95 \%$ underwent hypoxic challenge testing (HCT)? 2) Did all patients with a $\mathrm{Pa}_{1} \mathrm{O}_{2}$ of $6.7 \mathrm{kPa}$ (50 mmHg) during HCT fly with oxygen? 3) How many patients with an $\mathrm{Sp}, \mathrm{O}_{2}$ of $<92 \%$ at ground level flew without oxygen?

HCT is useful for predicting the level of hypoxaemia that patients will experience during a flight. However, it is not clear which patients should undergo $\mathrm{HCT}$, i.e. which patients are at risk of an in-flight $\mathrm{Pa}_{1} \mathrm{O}_{2}$ of $<6.7 \mathrm{kPa}(<50 \mathrm{mmHg})$. COKER et al. [1] reported that 19 of the 82 patients who underwent hypoxic challenge testing despite a ground-level $\mathrm{Sp}_{\mathrm{p}} \mathrm{O}_{2}$ of $\geqslant 96 \%$ did indeed experience severe hypoxaemia during the test. It would be interesting to characterise these patients. How do they compare to those of the same ground-level $\mathrm{Sp}, \mathrm{O}_{2}$ but without 